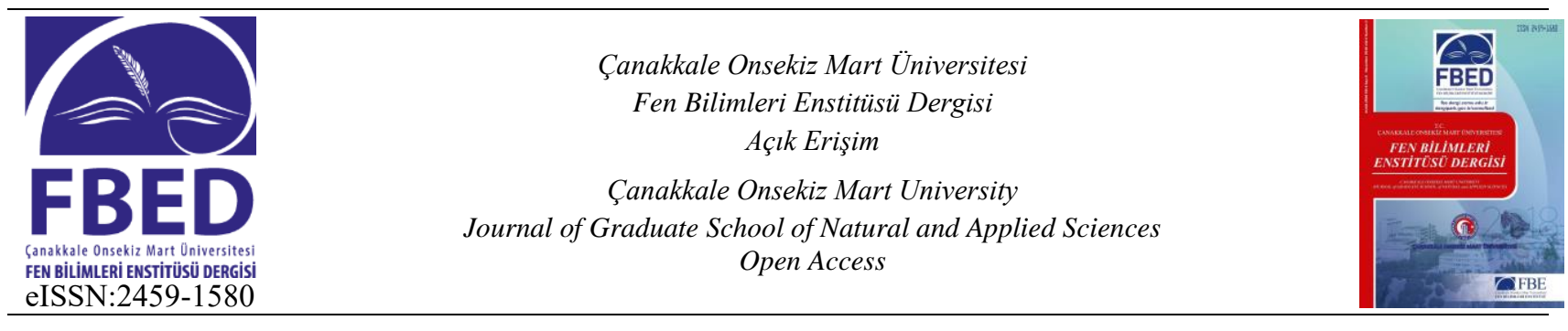

DOI: $10.28979 /$ comufbed.691614

2020, Cilt 6, Sayı 1, Sayfa: 166-179

dergipark.org.tr/tr/pub/comufbed

\title{
Kuzey Anadolu Fay Zonu'nun Kabuk Hızı Değişimlerinin Yoğun Sismik Dizilim ile İncelenmesi
}

\begin{abstract}
Ahu Kömeç Mutlu ${ }^{1}$, Musavver Didem Cambaz ${ }^{2}$
'İnşaat Mühendisliği Bölümü, Mühendislik Fakültesi, Gebze Teknik Üniversitesi, Çayırova, Kocaeli, Türkiye ${ }^{2}$ Kandilli Rasathanesi ve Deprem Araştırma Enstitüsü, Boğaziçi Üniversitesi, Çengelköy, Üsküdar, İstanbul, Türkiye

Makale Tarihçesi

Gönderim: $\quad 20.02 .2020$

Kabul: $\quad 18.05 .2020$

Yayım: $\quad 22.05 .2020$

Araştırma Makalesi

$\ddot{\mathbf{O} z}$ - Aktif fay zonları boyunca asimetrik olarak dağılmış olan mikro çatlaklar bu zonlardaki depremlerin tekrarl oluşumları nedeniyle meydana gelmektedir. Aynı bölgede sürekli tekrarlanan depremler, elastik olarak farklı olan malzemeleri ayırarak iki-malzemeli arayüzeyler meydana getirir ve deprem davranışını etkileyen önemli sonuçlar doğurur. Kuzey Anadolu Fay Zonu üzerinde kurulan DANA (Dense Array of Northern Anatolia) sismik ağı Kuzey Anadolu Fay Zonu'nun Sakarya ve Sapanca segmentleri üzerinde iki malzemeli arayüzeyin incelenmesi için elverişli veri sağlamaktadır. Bu çalışmanın amacı, yoğun sismik dizilim bulunan Kuzey Anadolu Fay Zonu'nun (KAFZ) batı ucunda Sakarya ve Sapanca segmentleri arasında, deprem dalgası çapraz ilişki analizleri kullanarak, iki malzemeli arayüzey geçişindeki hız değişimlerini belirlemektir. Araştırma kapsamında 2012-2013 yıllarında, çalışma alanında faaliyet gösteren DANA geçici sismik ağına ait 73 adet sismik istasyondan, 109 adet uzak deprem kaydı kullanılarak 50.000'den fazla dalga formu derlenmiştir. Uzak deprem dalgalarının, sismik kayıtçılara varışları arasındaki zaman farkları, fayın karşııkılı bölümlerinde kabuktaki hız kontrastını tespit etmek ve fark değerini ölçmek için kullanılmıştır. Elde edilen bulgular KAFZ kuzey kolunun kuzeybatısında düşük, kollar arası ArmutluOvacık bloğu altında yüksek hızlara işaret etmektedir. Referans kayıtçıların analizinde, hız oranlarında lokal değişimler hesaplanmış olsa da, bölge geneline bakıldığında KAFZ kuzey kolunun kuzeyi ile, yine KAFZ kuzey kolunun doğusu ve güney doğusu arasında görece büyük hız farkları elde edilmiştir. Sonuçlar, KAFZ kuzey ve güney kollarındaki hız değişimlerini ve genel tektonik ortamla ilişkilendirilen özellikleri ortaya koymaktadır.
\end{abstract}

Anahtar Kelimeler - Íki malzemeli arayüzey, hız farkı, Kuzey Anadolu Fay Zonu, Sakarya-Sapanca Segmenti, Türkiye

\section{An Investigation on the Crustal Velocity Variations of the North Anatolian Fault Zone by a Dense Seismic Array}

${ }^{1}$ Department of Civil Engineering, Faculty of Engineering, Gebze Technical University, Gebze, Turkey ${ }^{2}$ Kandilli Observatory and Earthquake Research Institute, Boğaziçi University, İstanbul, Turkey

Article History

Gönderim: $\quad 20.02 .2020$

Kabul: $\quad 18.05 .2020$

Yayım: $\quad 22.05 .2020$

Research Article

\begin{abstract}
Asymmetrical distribution of microfractures across the fault is the result of repeated occurrence of earthquakes on active fault zones. Earthquake sequences generate bimaterial interfaces which separate elastically different materials from each other and provide important implications for earthquake behavior. Dense Array of Northern Anatolia (DANA) network provides valuable data in order to investigate bimaterial interface across the north and south branches of North Anatolian Fault Zone (NAFZ) beneath Sakarya-Sapanca segments. The aim of this study is to determine velocity contrast along the north and south branches of NAFZ by using the dense temporary seismic DANA network along the western edge of NAFZ between Sakarya and Sapanca segments From May 2012 to September 2013, more than 50.000 waveforms are compiled from 109 teleseismic earthquakes and 73 stations of DANA temporary network operated in the study area. We used differences between arrival times to detect and quantify velocity contrast in crust across the fault. Although local changes in velocity ratios were found in reference station analyzes, overall velocity differences were observed beneath north of the NAFZ northern branch and relatively east and southeast of the NAFZ northern branch. It is possible to mention the presence of a twomaterial interface between the two branches of the fault. The results indicate the existence of biomaterial interface along the NAFZ branches which provides important implications for understanding the earthquake dynamics and mechanism.
\end{abstract}

Keywords - Bi-material Interface, velocity contrast, North Anatolian Fault Zone, Sakarya-Sapanca Segment, Turkey

\footnotetext{
(iD https://orcid.org/0000-0003-2243-7302 ahumutllu@gtu.edu.tr*

2 (D) https://orcid.org/0000-0001-5395-2388 didem.samut@boun.edu.tr

*Sorumlu Yazar / Corresponding Author
} 


\section{Giriș}

Büyük fay zonları, bulunduğu ortamdaki farklı litolojik birimleri ayıran iki malzemeli (bi material) arayüzlere sahiptir. $\mathrm{Bu}$ arayüzler büyük fay bloklarının uzun süreli tekrarlanan hareketi ile meydana gelmiştir. Fay zonlarında farklı kayaç türlerinin varlığı, yerel sismik ve jeodezik alanların özelliklerini değiştirmektedir (Najdahmadi vd., 2016). Bu değişimler ise fay zonundaki Moho derinliği, deprem odak mekanizmaları, yer hareketi büyütmesi ve uzak deprem dalgalarının gecikmesi ile ilgili belirleyici özellikler yansıtır. Bunun yanında sadece depremin dinamik özelliklerini değil, yayılma yönünü, yerel yapısal özelliklerini ve fay boyunca görülecek sismisiteyi de önemli ölçüde etkiler. Büyük fay zonlarında kayma zonu sıklıkla iki malzemeli arayüzlerden (Şengör vd., 2005; Dor vd., 2008; Mitchell, Ben-Zion ve Shimamoto, 2011; Özakın vd., 2012) geçmektedir. İki malzemeli arayüzler, deprem ve fay zonu sismolojisinde büyük rol oynayabilir. Deprem kaynak bölgelerinde görülen litolojik farklılıklar belirsizliklere neden olmaktadır. Son yıllarda yapılan arazi çalışmalarında gerilme ile oluşan mikro kırıkların, depremi oluşturan fayın ve fay kollarının etrafını sardığını göstermektedir (Yamashita, 2009). Böyle bir arayüzde meydana gelecek deprem yırtılması, mikro çatlaklar etkisinde ve tercihli yayılma yönüne sahiptir. Öte yandan, fay zonunun zıt taraflarında, hız farklılığı göz ardı edilirse, deprem bölgelerinde, fay düzlemi çözümlerinde ve kaynak mekanizması analizinde sapmalar ve hatalar oluşturabilir (Ben-Zion ve Malin, 1991; Ben Zion ve Andrews, 1998; Zaliapin ve Ben-Zion, 2011; Ben-Zion, 1989). Sismolojik analizler ve litolojik çalışmalara olan etkisi nedeniyle, günümüzde farklı dalga formları ve yöntemler ışığında yapılan iki malzemeli arayüz çalışmalarının sayısı gün geçtikçe artmaktadır.

Anadolu ve Avrasya levhalarını sinırlayan ve tekrarlı olarak $(M>7)$ depremler üreten Kuzey Anadolu Fay Zonu (KAFZ) en büyük yanal atımlı fay zonlarından birisidir. KAFZ boyunca oluşan büyük depremlerin 1939 Erzincan depreminden başlayarak doğudan batıya doğru göç etmesi İstanbul ve civarında başka büyük depremlerin oluşma potansiyelini arttırmaktadır (Barka ve Kadinsky, 1988; Barka, 1996). İzmit'de, 17 Ağustos 1999 depreminden sonra çeşitli sismik ağlar (DANA, 2012; Beck ve Zandt, 2005) kurularak KAFZ üzerindeki yırtılma bölgesinde çok sayıda çalışma yapılmıştır (Gülen vd., 2002; Barka vd., 2002; Nakamura vd., 2002). DANA (Dense Array for North Anatolia) projesi kapsamında toplanan veriler farklı çalışmalara kaliteli ve yoğun bir veri tabanı sağlamıştır (Altuncu vd., 2015; Frederiksen vd., 2015; Kahraman vd., 2015; Taylor vd., 2018). Bu veri seti kullanılarak KAFZ'nin ilgili bölgesinde çeşitli sismolojik çalışmalar yapılmış, bölgenin mikro-sismisitesi (Altuncu vd., 2015), alıcı fonksiyon analizi (receiver function) detaylı olarak araştırılmış (Frederiksen vd., 2015). KAFZ'nin her iki kolunda da 10 km'den sı̆̆ üst, orta ve alt kabukta, litolojik ve yapısal farklılıklar gözlenmiştir. H-k yığma yöntemi kullanılarak (Kahraman vd., 2015), P dalgası uzak deprem kayıtlarından kabuk kalınlığı, tortul kalınlık ve P/S hız oranı hesaplanmıştır. Buna göre, güneyden kuzeye doğru 30 km'den 45 km'ye kadar artan kabuk kalınlıkları ve KAFZ'nin güney kolunun güneyinde dramatik olarak artan P/S hızı gözlemlenmiştir. Aynı veri seti kullanılarak, (Taylor vd., 2018) İzmit-Adapazarı bölgesi altında çevresel gürültü değerleri kayıt edilmiş ve kesme dalgası hızı ilk 10 km'lik derinlik için görüntülenmiştir. Sedimanter havzalarla ilişkili olarak, Adapazarı havzasının altında düşük $S$ dalga hızları gözlenirken, KAFZ'nin iki kolu arasında nispeten yüksek hızlar tespit edilmiştir. Bu tür yoğun sismik ağ dizilimleri kullanılarak çalışma alanının sismik hızlarının yüksek çözünürlükle belirlenmesi sismolojinin yaygın çalışma konularındandır (Taylor vd., 2018; Delph vd., 2015; Karabulut vd., 2015; Papaleo, Cornwell ve Rawlinson, 2017; Özer ve Polat, 2017).

$\mathrm{Bu}$ çalışmada, yoğun sismik veri seti kullanılarak KAFZ kuzey ve güney kolları arasındaki hız farklılıkları incelenmiştir. Bölgeye yerleştirilmiş çok yoğun geniş bantlı deprem kayıt cihazı dizilimi, fayın kuzey ve güney kolları altında sismojenik derinlikteki iki-malzemeli arayüzü ve hız farklılıklarını incelemek için önemli avantaj sağlamıştır. Çalışmanın amacı, KAFZ'nin bu iki kolu arasındaki hız farkları değişimini araştırmaktır. Çalışma sonucunda elde edilen hız kontrastı bilgisi, fay üzerinde deprem kırılmalarındaki yönlülüğe (ve böylece yanal yönler boyunca sarsıntı zararlarının tahmin edilmesine) ayrıca çalışma alanının sismotektoniğinin daha iyi anlaşılmasına ve deprem sismik risk haritalarının geliştirilmesine önemli katkı sağlayacaktır. 


\section{Jeoloji ve Tektonik}

Afrika, Arap ve Avrasya levhalarının yakınsaması ve Anadolu'nun batıya hareketi Doğu Akdeniz'de levha sınırlarının gelişmesine neden olur (Özbakır, Govers ve Wortel, 2017). Türkiye, Alp Himalaya kuşağı üzerinde bulunan, birçok sismik zonu içerisinde bulunduran, sismolojik olarak aktif bir bölgede yer almaktadır. Türkiye'nin anakarası Tetis okyanusu havzalarının kapanmasının sonucu bir araya gelen çeşitli kıta ve okyanus parçaları ile şekillenmiş, dünyadaki en dinamik, karmaşık ve sismik olarak aktif neotektonik bölgelerden biridir. Bu bölgeyi şekillendiren yüzeyler karmaşık bindirme zonları ile birbirinden ayrılır ve baskın jeolojik geçmişleriyle karakterize edilir.

Türkiye'nin anakarasının kuzeyindeki Pontidler ve güneyindeki Tauridler İzmir-Ankara-Erzincan bindirme zonu ile birbirinden ayrılmaktadır. Kuzeybatı Anadolu, kuzeyden güneye ayrılan üç ana tektonik birim ile tanımlanmaktadır: (1) İstanbul Zonu, (2) Armutlu-Ovacık Zonu ve (3) Sakarya Zonu (Okay, 1989). (Şekil 1). $\mathrm{Bu}$ üç zona ait kayaçlar günümüzde KAFZ'nun yer aldığı ve Erken Eosen-Oligosen'de Intra-Pontid okyanusunun kapanması sonucu oluşan kenet boyunca bir araya gelmiştir (Şengör ve Y1lmaz, 1981) İstanbul zonu Ordovisiyen-Alt Tersiyer yaşlı tortul kayalardan oluşur, Sakarya zonu ise metamorfik temel ile JuraKretase yaşlı tortul örtüden oluşur (Yılmaz vd., 1999; Erturaç K., 2018a) Adapazarı-Pamukova benzeri genç tektonik ovalar ve civarında ise Pliyosen-Kuvaterner yaşlı birimler gözlenir (Erturaç K., 2018a). ArmutluOvacık zonu, İstanbul ve Sakarya zonlarının tektonik bir karışımını temsil eder ve tektonik olarak sınırlandırılmış gibi görünür. Bu zon, yığışım kompleksi olarak oluşan yüksek topografyaya sahiptir. Armutlu-Ovacık Bölgesinin doğu-batı eğilimi yaklaşık $20 \mathrm{~km}$ ile $50 \mathrm{~km}$ genişliğindedir (Elmas ve Yiğitbaş, 2001). Yaklaşık $2 \mathrm{~km}$ tortul kalınlığına sahip olan Adapazarı havzası bu bölgede yer almaktadır. Güneyde Sakarya Bölgesi, İzmir-Ankara-Erzincan bindirme zonunun melanj ve ofiyolitleri ile sinırlanan doğu-bat1 eğilimli bir kıta parçasıdır (Şekil 1). Çok farklı özellikteki jeolojik birimleri bir arada barındıran çalışma alanında, yer süreçlerine ilişkin çeşitli jeomorfolojik özellikler de çok yakın alanda iç içe bulunmaktadır ve yer şekillerinin oluşumları bu bölgede hala devam etmektedir (Eturaç K., 2018b).

Doğuda Karlıova ilçesinden, batıda Saros Körfezi'ne kadar uzanan Kuzey Anadolu Fay Zonu, yaklaşık 1200 km uzunluğundadır. KAFZ, Karlıva'dan 1999 İzmit deprem yırtılmasının doğusuna kadar oldukça süreklidir. Yaklaşık $80 \mathrm{~km}$ sağ yanal atım ve 2,4 cm/yıl hareket oranı ve mevcut kayma oranı yaklaşık 20-30 mm/yıldır (Şengör vd., 1985; Reilinger vd., 1997; Armijo vd.,1999a, 1999b; McClusky vd.,2000). Bolu'nun doğu ucundan itibaren fay iki ana kola ayrılır. Güney kolu, kuzey kolundan $(\sim 25 \mathrm{~mm} / \mathrm{y} 1)$ daha düşük kayma oranına ( 5-10 mm/yıl) sahiptir (Meade vd., 2002). Kuzeybatı Anadolu'daki üç ana tektonik birim, Kuzey Anadolu Fay Zonu bölgesinin bu iki kolu tarafından sınırlanmaktadır. Kuzey kolu, Düzce-Karadere segmentini Adapazarı havzası boyunca takip ederek Marmara Denizi'ne girer. Güney kolu, Pamukova boyunca ilerleyerek İznik Gölü'nden Gemlik Körfezi'nde kadar uzanmaktadır (Barka ve Kadinsky, 1988; Barka, 1996). Bu çalışma, kuzeyden güneye sırasıyla; İstanbul Zonu, Armutlu-Ovacık Zonu ve Sakarya Zonu'nu, kapsayan, kuzeybatı Anadolu'da yer almaktadır. 


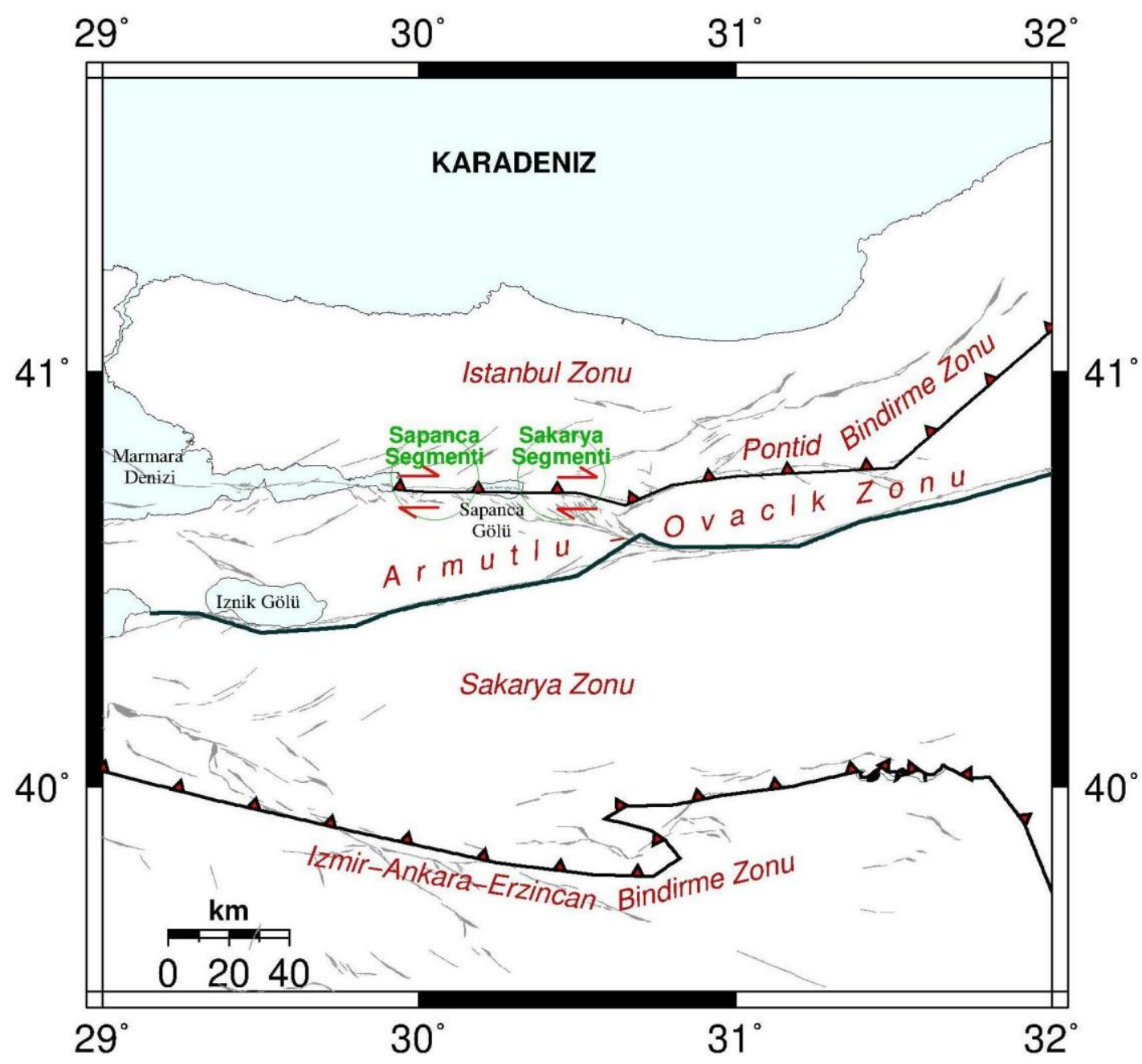

Şekil 1: Çalışma alanında hâkim olan tektonik yapı gösterilmiştir. Siyah çizgiler İstanbul Zonu, ArmutluOvacık Zonu ve güneyde Sakarya Zonu tektonik sınırlarını göstermektedir. Bindirme zonları kırmızı üçgenli siyah çizgi ile gösterilmiştir. KAFZ üzerinde yer alan Sakarya ve Sapanca segmentleri şekilde belirtilmiştir. Güncel fay haritası bilgisi Emre vd., 2013 makalesinden alınmıştır (Emre vd., 2013; Cambaz ve Karabulut, 2010).

\section{Veri ve Yöntem}

DANA sismik ağı Mayıs 2012 ile Eylül 2013 tarihleri arasında, Sakarya-Adapazarı bölgesinde, 16 aylık bir süre boyunca işletilmiştir. Sismometreler, KAFZ'nun her iki kolunu dikey yönde kesecek ve sırasıyla kuzeyden güneye, üç ana tektonik birimi de içine alacak şekilde konumlandırılmıştır. Bu sismik ağ dizilimi ve istasyonların dağılımı KAFZ'nun her iki kolundaki hız değişimlerini bir arada incelemeye olanak sağlamıştır. Sismik ağ, birbirine paralel $7 \mathrm{~km}$ mesafeli ve her birinde 11 sismik istasyon içeren altı kuzeygüney hat çizgisinden oluşmuştur ve yaklaşık $70 \times 35 \mathrm{~km}^{2}$ dikdörtgen alanı kaplamıştır. Bu dizi, aynı zamanda doğuda bir yay oluşturacak şekilde yerleştirilen 7 istasyonla desteklenmiştir (Şekil 2). Diziye ait veri setine ek olarak, Boğaziçi Üniversitesi Kandilli Rasathanesi ve Deprem Araştırma Enstitüsü, Bölgesel Deprem ve Tsunami İzleme ve Değerlendirme Merkezi (Boğaziçi University, Kandilli Observatory and Earthquake Research Institute, 2001) tarafindan işletilen 13 adet kayıtçı cihazından toplanan veriler de bu çalışmada kullanılmıştır. Analizlerde 73 adet (54 CMG6T, 6 CMG3TD, 2 CMGESPD, 1 CMG40TD) genişbant istasyonundan toplanan yüksek kaliteli dalga formu verileri kullanılmıştır. Bu istasyon dağılımı, sadece KAFZ ve Adapazarı havzasının her iki ana kolundan da geçmekle kalmayıp çalışma alanındaki farklı jeomorfolojik yapıları da içine almaktadır. 
Çalışma alanındaki akma (creep) etkisinden dolayı bölgedeki sismik aktivitenin yoğun olmadığı daha önceki çalışmalarda değinilmiştir (Aslan vd., 2019; Martinez-Garzon vd., 2019). Çalışma alanının asismik özelliğinden dolayı, bu çalışmada, analizlerin yapılmasına yetecek kadar lokal deprem meydana gelmemiş ve çalışmada uzak deprem dalga formu varışları kullanılmıştır. Uzak deprem kayıtları, merkez üssü mesafesi 30 dereceden büyük ve 100 dereceden küçük, deprem büyüklügü ise 5.5 'den büyük olacak şekilde filtrelenmiş ve toplam 109 adet uzak deprem dalga formu varışı analizlerde kullanılmıştır. Deprem kataloğu, USGS (The United States Geological Survey) kataloğundan üretilmiştir (https://earthquake.usgs.gov/-earthquakes/) (Şekil 3).

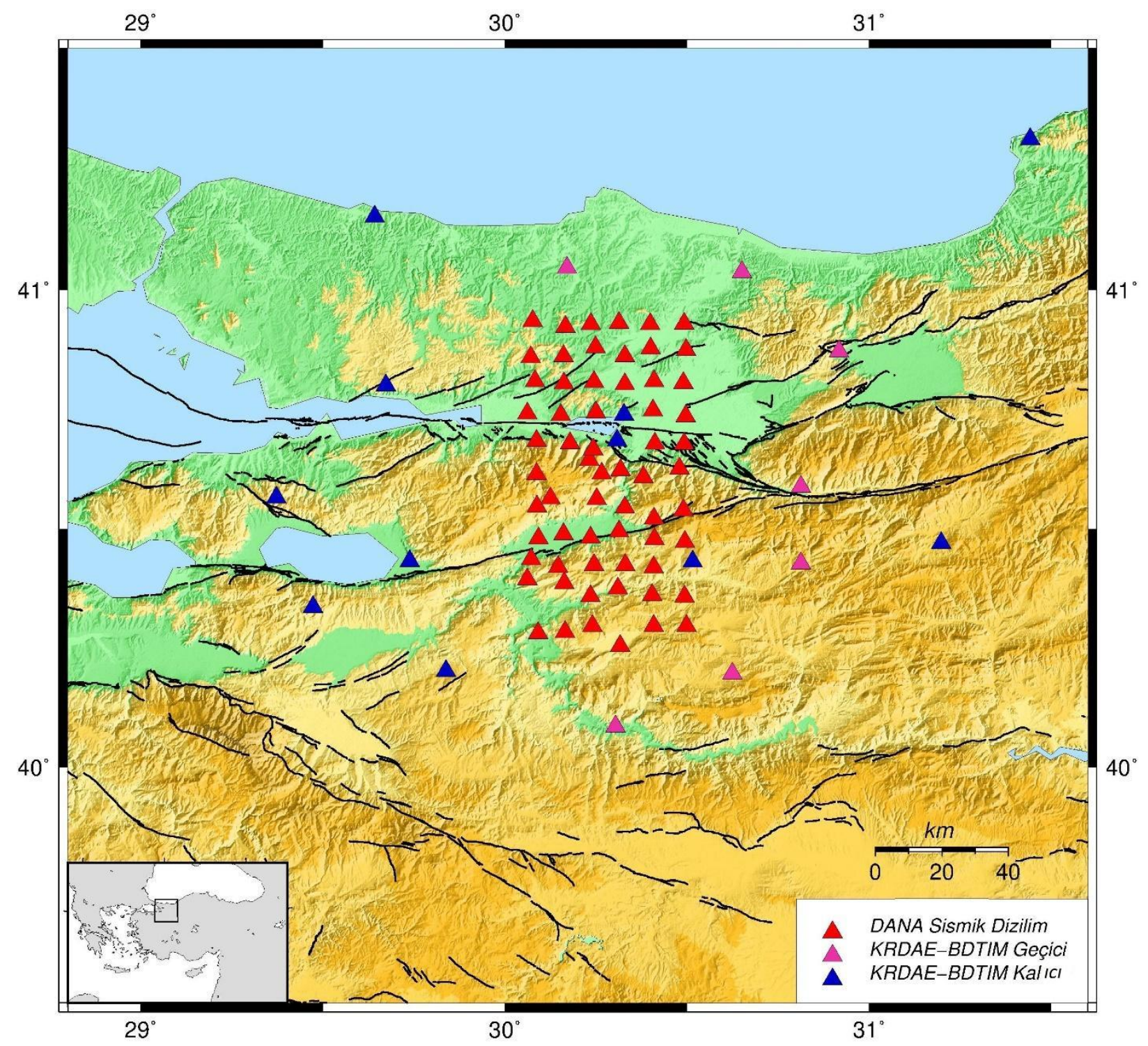

Şekil 2: Sismik istasyon dağılım haritası. Üçgenler geniş bantlı istasyonların yerlerini göstermektedir. Çalışma alanının konumu sol alt şekilde dikdörtgen çerçeve içerisinde gösterilmiştir. 


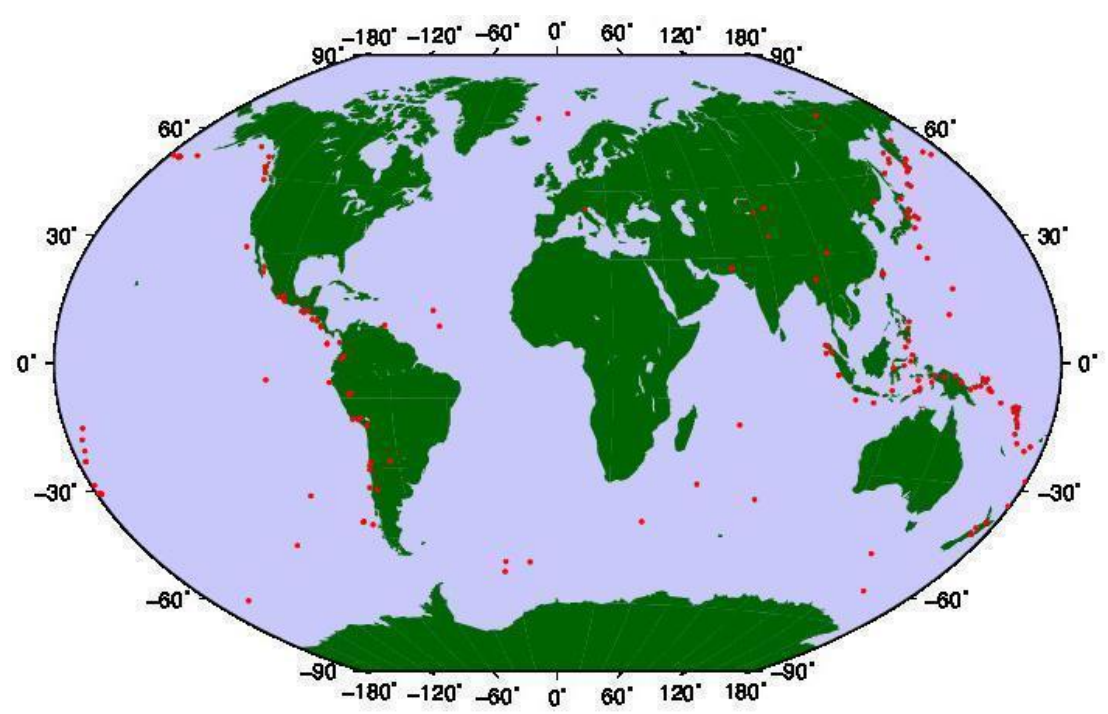

Şekil 3: USGS kataloğu (https://-earthquake.usgs.gov/earthquakes/) kullanılarak hazırlanan telesismik deprem dağılım haritası. Daireler 2011-2013 yılları arasında dünyada meydana gelmiş, merkez üssü uzaklığ1 $30^{\circ}$ ile $100^{\circ}$ arasında olan, $\mathrm{M}>5,5$ depremlerin yerlerini işaret etmektedir.

Bu çalışmada, Sakarya ve çevresine yerleştirilen sismik istasyonlarda kayıt edilen 2011-2013 yılları arasında meydana gelmiş $(M>5.5)$ depremlerin, gözlemlenen uzak deprem dalgası seyahat süreleri ile beklenen uzak deprem dalgası seyahat süreleri arasındaki farklar hesaplanmıștır. Deprem kaynağında yayılan sismik dalgaların geliş açısı, istasyon konumuna bağlı olarak farklılıklar göstermektedir. Ancak istasyona neredeyse dikey yönde ulaşan uzak deprem dalgaları için, dalga formunun istasyon çiftlerine aynı geliş açısı ile geldiği varsayılmıştır $(\cos \Theta=1)$. Ölçümlerde farklılıklar gösteren seyahat süreleri kabuk kalınlığı farklılıkları, istasyon dağılımı geometrisi, istasyonlar arasındaki yükseklik farkından kaynaklanıyor olabileceği gibi doğrudan kabuk hızı farklılıklarından da kaynaklanıyor olabilir. Bu nedenle çalışmada diğer etkiler minimize edilerek kabuk hızından kaynaklanan farklılıkların görüntülenmesine özen gösterilmiştir.

Kabuk kalınlığı Türkiye'nin batısında ve doğusunda belirgin değişiklikler göstermektedir (Cambaz ve Karabulut, 2010). Sakarya ve civarındaki bölgenin kabuk kalınlığı çeşitli çalışmalar sonucunda 30-45 km aralığında bulunmuştur (Karabulut vd., 2019; Tezel vd., 2013; Vanacore vd., 2013; Mutlu ve Karabulut, 2011). Çalışma alanı, Adapazarı havzasının kuzeyinde ve güneyinde, tortul tabakaların ve tepelerin olduğu bir bölgedir. Bu nedenle, sismik kayıtçı cihazlar arası yükseklik farkları, topoğrafyanın etkisi nedeniyle \%50 oranına ulaşabilmektedir. Bu yükseklik farkından doğabilecek hataları engellemek için her bir istasyon için, o istasyon altındaki Moho kalınlığı (Frederiksen vd., 2015; Salah vd., 2007) kullanılarak hız modeli yeniden hesaplanmıştır. Ayrıca her istasyon için (piercing point) atım noktası hesaplanarak kot farkından kaynaklı ışın yolu düzeltmesi yapılmıştır ( $\mathrm{r} . \sin \Theta$ değeri seyahat zamanına eklenmiştir). Böylece kot farkından oluşabilecek sistematik hataların da önlenmesi hedeflenmiştir. İki istasyon arasındaki gözlemlenen ve tahmini varış zamanları $(\Delta \mathrm{t} 1-2)$, mevcut tüm dalga formları için dalga şekli çapraz korelasyonu kullanılarak hesaplanmıştır (Özakın vd., 2012). Standart sapması 0,15sn'den büyük ve 5'den az ölçümü olan istasyon çiftleri hesaplamalara katılmamıştır. Toplam 73 istasyonda 5329 adet varış zamanı farkı hesaplanmışı̧ır. Elde edilen zaman farklarını hız oranlarına dönüştürmek için aşağıdaki formülasyon kullanılmıştır.

$$
\frac{V_{1}}{V_{2}}=\frac{h_{1}}{h_{2}+\Delta t_{1-2} V_{m} \cos (\theta)}
$$

$\Delta \mathrm{t} 1$-2: istasyon çifti için varış zamanı fark1, h1 ve h2: 1. ve 2. kayıtçıların kabuk kalınlığ1, V1 ve V2: sırasıyla 1. ve 2. kayıtçılardaki P dalga hızları (Vm değeri çalışma alanı altında Pn hızı 7.32 sabit alınmıştır (Teoman vd., 2014), $\Theta$ : varış açısı (uzak deprem kayıtları neredeyse dik geldiği için her kayıtçı altında eşit kabul edilmiştir ve $\cos \Theta=1$ olarak alınmıştır) (Teoman vd., 2014). 
Çalışmada yapılacak hesaplamalarda hız kontrastının yalnızca kabukta meydana geldiği varsayılmıştır. Bunun yanı sıra Moho tabakasının düz olmadığı, çalışma alanında değişkenlik gösterdiği de yapılan varsayımlar arasındadır. Bölgenin altındaki kabuk kalınlığının güneyden kuzeye doğru yaklaşık 7 km kadar artmakta olduğu bilinmektedir (Frederiksen vd., 2015). Bölgenin altındaki tortul kalınlı̆̆ının 1,5 ile 5,5 km arasında değiştiği gözlenmiştir. Yapılacak hesaplarda ortalama bir tortul kalınlığı, Moho derinliği veya ortalama P dalga hızı kullanılması, farklılıkların sadece ortam hızlarından olup olmadığını anlamada karmaşıklığa yola açacaktır. Çalışma alanı için istenilen detayda tortul tabakası kalınlığı bulunamadığından ve varış zamanı hesaplamalarında tortul tabakası etkisini en aza indirgenmesi istendiğinden varış zamanı hesaplamalarında tortul tabaka etkisinin en aza indirilmesi için DANA ağını kullanarak hesaplanan (Teoman vd., 2014) beş katmanlı kabuk modeli kullanılmıştır (Tablo 1).

Tablo 1

Teoman vd., 2014 çalışmasından elde edilen kabuk modeli verilmiştir. Kabuk dışından kaynaklı fazlar için AK135 hız modeli kullanılmıştır.

\begin{tabular}{|c|c|}
\hline Derinlik $(\mathrm{km})$ & P dalga hızı $(\mathrm{km} / \mathrm{s})$ \\
\hline 0 & 4.38 \\
\hline 2 & 5.67 \\
\hline 12 & 6.57 \\
\hline 24 & 6.96 \\
\hline 30 & 7.32 \\
\hline
\end{tabular}

\section{Sonuçlar ve Değerlendirme}

Uzun yıllar boyunca yırtılma geçmişi olan fay zonları genellikle farklı elastik parametrelere sahip ara yüzeyler oluştururlar. İki malzemeli ara yüzey üzerine bugüne kadar yapılan çalışmalar, büyük fay zonlarındaki deprem yırtılmalarının hız yapısı ile ilişkili bir öncelikli yayılma doğrultusu olduğunu işaret eder. Bu çalışmalar, jeomorfolojik asimetriyi ortaya koymada önemli bir rol oynamaktadır. Bu çalışmada ele alınan çalışma alanı jeomorfolojik olarak çok çeşitli özellikleri bir arada içeren çok kompleks yapıda bir alan olmasından dolayı yöntemin başarısının test edilmesi için de oldukça elverişli bir zemin oluşturmaktadır. Çalışma alanında dağlar (Samanlı dağları, Almacık dağı) ve ovalar (Adapazarı ovası, Pamukova) çok dar bir alanda iç içe geçmiş olduğundan, topoğrafya belirgin ölçüde farklılık göstermektedir bu nedenle bölgedeki topografik özellikler dikkate alınarak kayıtçı istasyonlar altında topoğrafya düzeltmesi yapılmıştır. Kıtasal kabuk kalınlıklarındaki farklılıklardan kaynaklanabilecek sistematik hataları önlemek amacıyla Frederiksen vd., (2015) tarafından gözlemlenen kabuk kalınlıkları kullanılarak, her kayıtçı için kabuk hızı düzeltmesi yapılmıştır.

Yoğun sismik dizilim içerisinden seçilen istasyon çiftleri için hız oranları grafiklerinden karşılaştırma yapılarak sonuçlar yorumlanmaya çalışılmıştır. Her seferinde farklı bir kayıtçı referans alınarak, hız oranı değişimleri hesaplanmıştır. Bazı kayıtçılarda gürültü problemleri ve veri kayıplarından dolayı istasyon çiftlerinde hız değişim oranları hesaplanamamıştır. Bu kayıtçı çiftleri şekillerde gri renk ile kodlanmıştır (Şekil 4-6). Dizilim KAFZ'nin her iki kolunu KG yönlü kestiği için diziliminin kuzey ve güney uçlarında seçilen kayıtçılar, dizilim dışından seçilen kayıtçılarla desteklenerek yorumlamaya gidilmiştir. Dizilimin KAFZ'nin kuzey ve güney kolları üzerine konumlanmış olan kayıtçılardan elde edilen hesaplamalar, dizilimin doğusunda yer alan KOERI sabit kayıtçı verisi ile desteklenerek yorumlanmıştır.

Şekil 4'de KO04 ve DF07 istasyonlarından hesaplanan hız oranları gösterilmektedir. Bu istasyonların her ikisi de bölgede Armutlu-Ovacık zonu olarak tanımlanan alana denk gelmektedir. Bu alan doğu ve batı yakasında yüzeylenen ofiyolitik birimler predotit, gabro, amfibolit, şist, gnays ve metaperidotitlerden oluşur ve ofiyolitik kayaçların egemen olduğu tektonik bir karmaşıktır (Erturaç K., 2018). KO04 Almacık dağı, 
DF07 ise erken kretase geç eosen dönemi flişeri olarak tanımlanan yere denk gelmektedir. Kayıtçı dizilimin doğusunda bulunan KO04 kodlu KOERI sabit kayıtçısı referans alınarak yapılan analizde KAFZ kuzey kolunun kuzeyinde düşük hız oranları gözlenmiştir (Şekil 4). Kuzey kolun kuzeyinde, doğu-batı yönlü hız oranın değişimleri göze çarpmaktadır. Bu değişim, Papaleo vd., (2017) bulunan ve 1999 İzmit depremi kırığı ile ilişkilendirilen yanal hız farklılıklarıyla da bölgenin detaylı jeolojik haritalarında görülen farklı zamanlara ait sedimanter birimlerdeki değişikliklerle de uyumludur. Kuzey ve güney kollar arasına bakıldığında, buradaki jeolojik birimler İznik metamorfik birimleri ile ve erken eosen-geç kretase dönemi flişler ile temsil edilmektedir (Yılmaz vd., 1997). Hem DF07 hem de KO04 istasyonlarında hesaplanan hiz oranlarına bakıldığında hız oranlarının arttığı gözlenmektedir. Armutlu-Ovacık zonunun fayın iki kolu arasında kalan kesimi, etrafına göre nispetendaha dirençli jeolojik yapıya sahiptir (Papaleo vd., 2017). Bu özellik görece yüksek hız oranlarının varlığını destekler niteliktedir. Benzer şekilde dizilimin içindeki DF07 kayıtçısının referans alındığı hesaplamalarda da KAFZ kuzey kolunun kuzeyinde düşük hızlar, güneyinde yüksek hızlar elde edilmiştir (Şekil 4). Bu farklılıkların da detaylı jeoloji haritasındaki jeolojik birimlerde gösterilen değişimlerle uyum içerisinde olduğu görülmüştür. Burada kuzey kol boyunca iki malzemeli arayüzden bahsetmek mümkündür. Hesaplamalarda kullanılan Moho derinlikleri, KO04 ve DF07 kayıtçıları için sırasıyla, $38 \mathrm{~km}$ ve $40.5 \mathrm{~km}$ 'dir (Frederiksen vd., 2015).
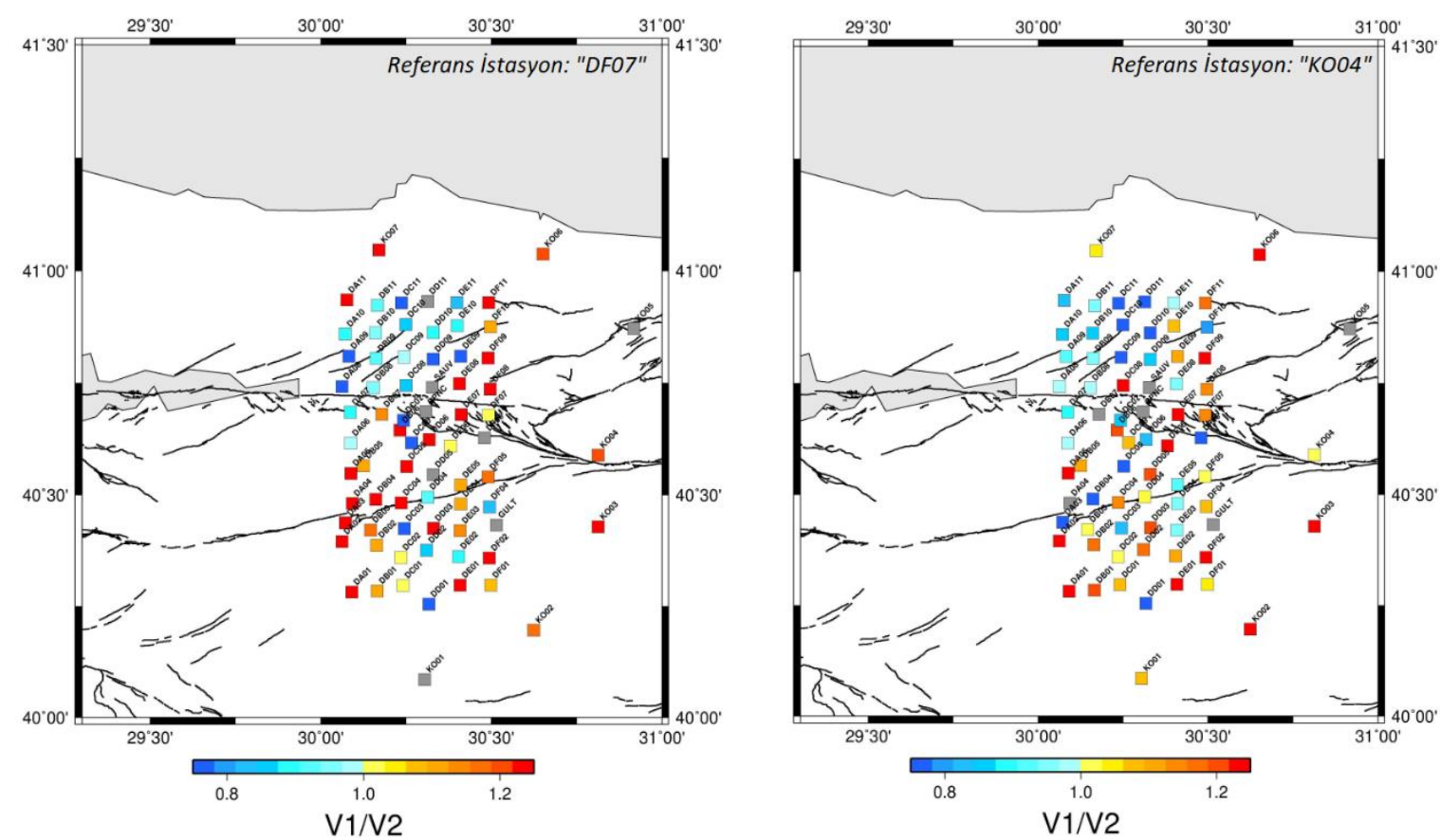

Şekil 4: DF07 KO04 kayıtçıları için hesaplanan hız oranları (V1/V2) değişimleri gösterilmiştir. Kayıtçı konumları renkli kutucuklarla temsil edilmektedir. Kayıtçı isimleri şekil üzerinde belirtilmiştir. Hız oranı 0,75 ile 1,25 değerleri arasında renklendirilmiştir. Gri renk ile gösterilen kayıtçılar veri yetersizliğinden dolayı hız değişimi hesaplanamayan kayıtçıları göstermektedir.

DANA diziliminin güneyinde konumlanan kayıtçılarda yapılan hesaplamalarda, DA01 ve KO01 kayıtçıları referans alınarak elde edilen hız oranları Şekil 5'te sırasıyla gösterilmiştir. DA01 kayıtçısı referans alındığında, hız değişimleri lokal farklılıklar göstermektedir. KAFZ kuzey kolunun kuzeyine bakıldığında, doğu-batı yönünde, batıda görece yavaş olmak üzere, hız farklılıkları görülmektedir. Fayın kuzey ve güney kolları arasındaki hız farkı geçişleri görece azdır. Dizilimin güneyinde kalan KO01 kayıtçısının referans tutulduğu analiz sonucunda, güney kol çizgisi boyunca gözlenen hız değişimi görece belirgindir. Güney kol boyunca hızların arttığı gözlenmektedir. KO01 ve DA01 kayıtçılarında Moho derinlikleri sırasıyla, 35.0km ve $34.5 \mathrm{~km}$ 'dir (Frederiksen vd., 2015).

Pontidler ile Anatolid-Torid kuşakları arasında, Sakarya Zonu'nun temelinde yer alan Permo-Triyas yaşl1, yer yer metamorfik ve/veya şiddetli deformasyon geçirmiş, içinde değişik yaş ve boyutta kireçtaşı blokları 
bulunduran kumtaşı, şeyl, bazik volkanit ve kireçtaşı ardalanmalı kayaç toplulukları Karakaya Grubu olarak tanımlanmaktadır. Sakarya ilinin en güneyinde Göynük Çayı Vadisi ve Pamukova arasındaki yükselimin zirvelerinde bu grubun üyeleri yüzeylenmektedir. Bunlardan ilki sedimanter ve bazik volkanik kayaç ardalanmasının yeşilşist fasiyesinde metamorfizması sonucu klorit-serisit şist, fillat, metabazik lav, kalkşist ve mermer litolojisine başkalaşmasıyla oluşan Gökçekaya Metamorfitleridir (Erturaç K.,2018).

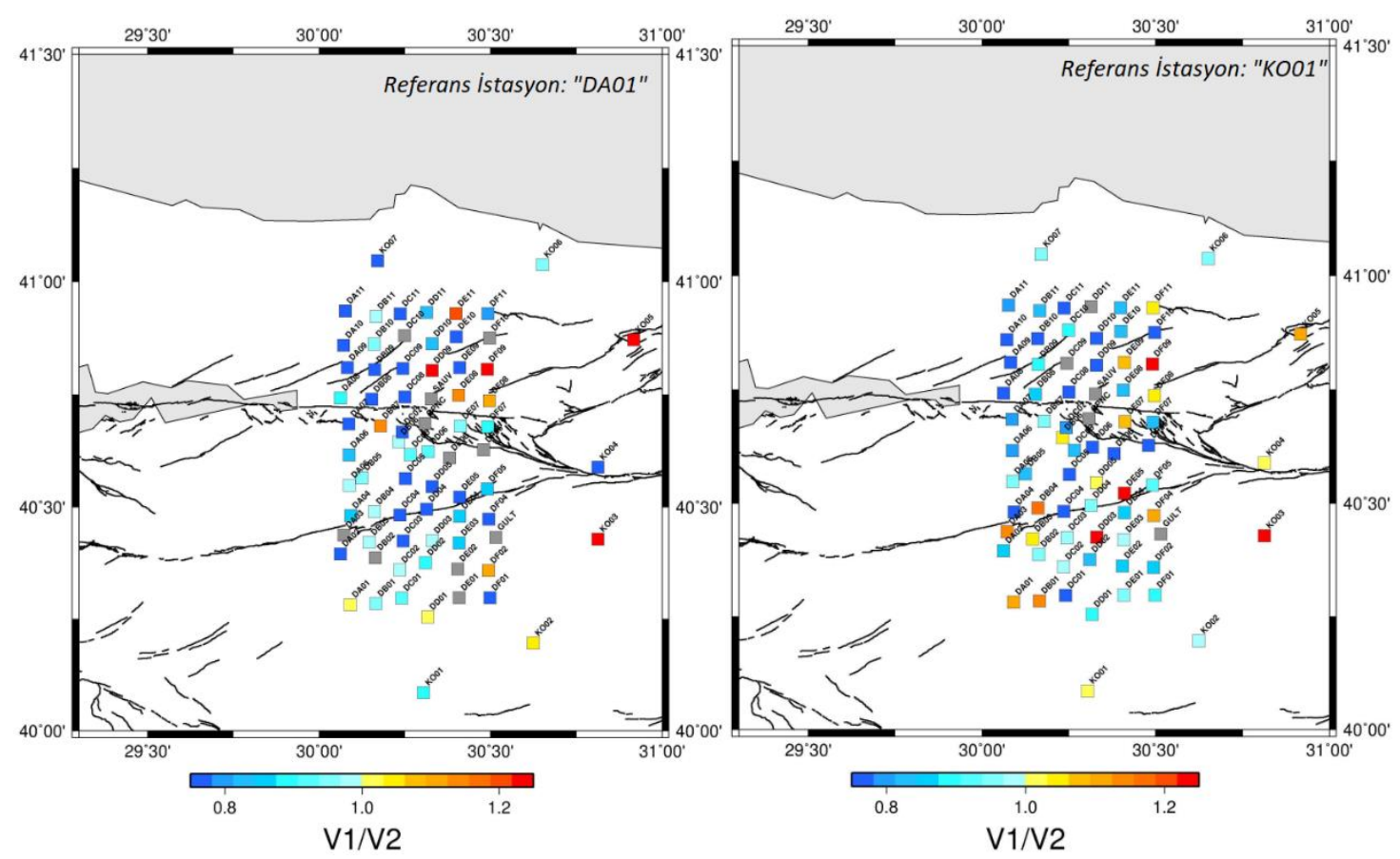

Şekil 5: DA01 ve KO01 kayıtçıları için hesaplanan hız oranları (V1/V2) gösterilmiştir. Kayıtçı konumları renkli kutucuklarla temsil edilmektedir. Kayıtçı isimleri şekil üzerinde belirtilmiştir. Hız oranı 0,75 ile 1,25 değerleri arasında renklendirilmiştir. Gri renk ile gösterilen kayıtçılar veri yetersizliğinden dolayı hız değişimi hesaplanamayan kayıtçıları göstermektedir.

Dizilimin kuzeyinde KO07 ve DF11 kayıtçıları seçilerek, hız oranları haritalanmıştır (Şekil 6). Her iki kayıtçı için yapılan hesaplamalarda kullanılan Moho derinlikleri 35.5 km'dir. KO07 kayıtçısı referans alındığında, KAFZ'nin kuzey kolunun kuzeybatısında hızlar görece düşüktür. KAFZ'nin kolları arasında ve güney kolun güneyinde sismik hızlar artmaktadır. DF11 kayıtçısının referans alındığı durumda da benzer değişiklikler gözlenmiştir. Papaleo vd., (2017) ve Frederiksen vd., (2015) çalışmalarına benzer şekilde, Güney kolun güneyinde görece düşük hızlar gözlenmesi, mafik malzemenin yoğun olarak görünmesi ile ilişkilendirilebilir. Salah vd., 2007 tomografi çalışmasında da bölgede belirgin P/S hız oranının değişimi gözlenmiştir. 


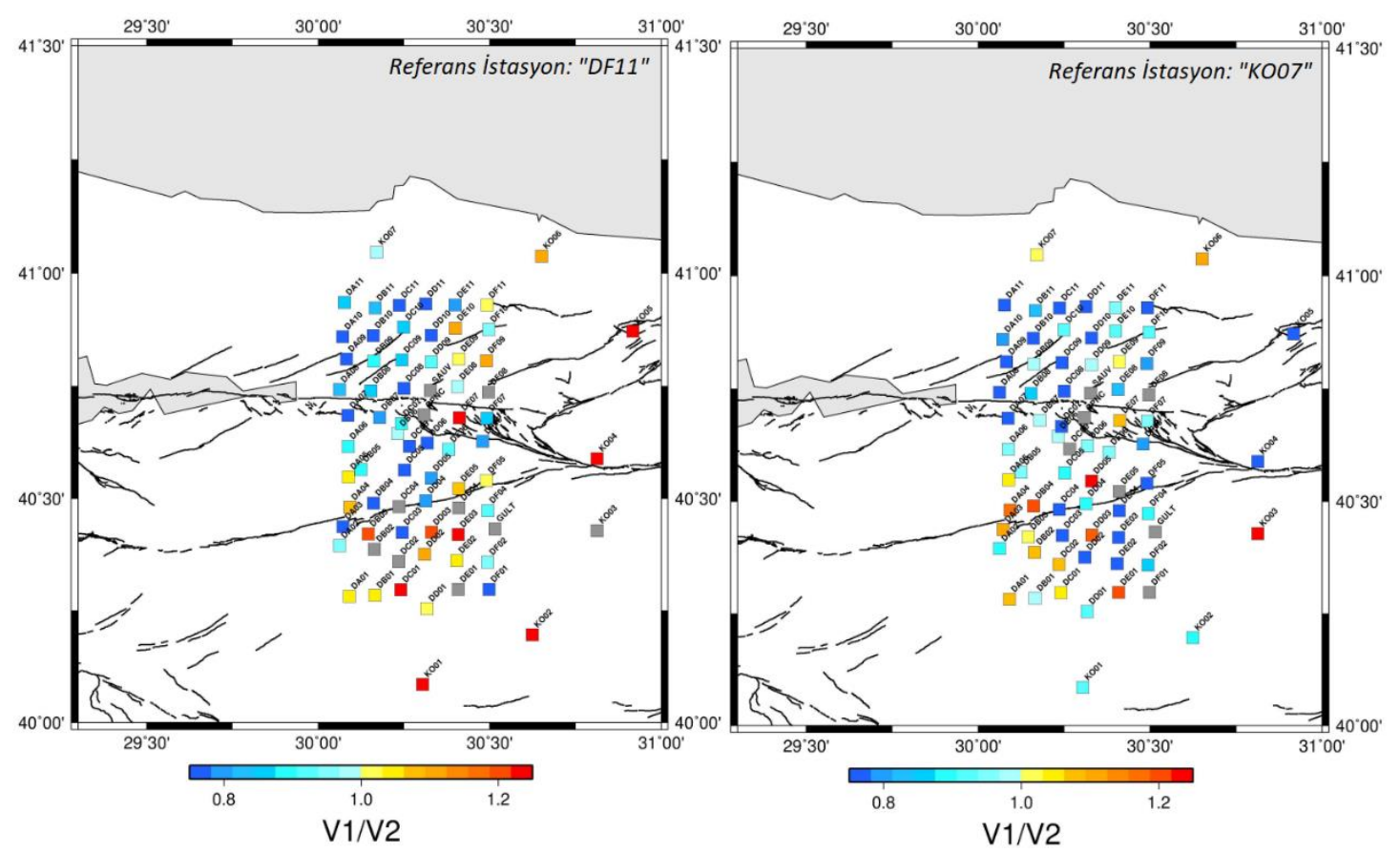

Şekil 6: DF11 ve KO07 kayıtçıları için hesaplanan hız oranları (V1/V2) gösterilmiştir. Kayıtçı konumları renkli kutucuklarla temsil edilmektedir. Kayıtçı isimleri şekil üzerinde belirtilmiştir. Hız oranı 0,75 ile 1,25 değerleri arasında renklendirilmiştir. Gri renk ile gösterilen kayıtçılar veri yetersizliğinden dolayı hız değişimi hesaplanamayan kayıtçıları göstermektedir.

Her 6 referans kayıtçı analizlerine bakıldığında lokalde hız oranlarındaki değişiklikler saptanmış olsa da bütüne ve genele bakıldığında belirgin hız farklarının elde edildiği konum KAFZ kuzey kolunun kuzey batısı ile görece doğu ve güneydoğusudur. Fayın her iki kolu arasında iki malzemeli arayüzey varlığından bahsetmek mümkündür.

Elde edilen sonuçlar, genel olarak KAFZ kuzey kolunun kuzeybatısında kalan kayıtçılarda düşük hızların gözlendiği yönündedir. KAFZ'nin kuzey kolunda güney kola oranla görece daha belirgin hız değişimleri saptanmıştır. Gözlenen hız farkları, kuzey kolun kuzeyindeki sığ sismisite ile uyum göstermektedir. Tank vd., (2005) tarafindan gözlemlenen rezistivite farkları, Papaleo vd., (2017)'nın telesismik tomografi çalışmasından elde edilen hız farkları, bölgenin altında, KAFZ'nin kuzey kolu boyunca, gözlemlediğimiz hız değişimleri ile benzerlik göstermektedir.

Adapazarı havzası altında, hız farkları göreceli olarak yumuşak (smooth) geçişlidir. Bu geçiş, havza altında tortul tabakanın varlığıyla uyumlu olup, metamorfik bloğu ve kalın sedimanter dizilim ile açıklanabilir (Elmas ve Yiğit, 2001). KAFZ'nin iki kolunun altındaki yap1, iki kol arasındaki farklı kayma oranlarının neden olduğu zorlanma nedeniyle oldukça karmaşıktır. Bu bölgenin altındaki hız farkları, güney kol şeridinin güneyinden daha büyüktür (Şekil 5, Şekil 6). Bunun nedeni, KAFZ kolları arasındaki alanın altındaki gerilmeye karşı kıtasal blok direnci olabilir. Papaleo vd., (2017)'de, Sakarya baseni altında nispeten düşük P hızları gözlemlemişlerdir. Bu gözlem, kuzeyden güneye artan hız oranı ile tutarlıdır (Frederiksen vd., 2015).

Bu çalışma kapsamında, KAFZ boyunca Sakarya-Sapanca segmentinin altında iki malzemeli arayüzü gözlenmiştir. Sonuçlar, KAFZ'nin özellikleriyle ve ayrıca çalışma bölgesinin yakınında yapılan önceki çalışmalarla uyumlu ve tutarlıdır. Elde edilen sonuçlar deprem kırılma mekanizması ve dinamiğini anlamada önemli bilgiler içerir. Bununla beraber, deprem lokasyonu, fay düzlemi çözümleri ve kaynak analizi çalışmalarında sistematik hataların önüne geçilerek bu hataların minimize olmasına imkân sağlayacaktır. 


\section{Teşekkür}

Natural Environment Research Council (NERC), İngiltere Doğal Çevre Araştırma Konseyi'ne (NERC), Leeds Üniversitesi'ne, Boğaziçi Üniversitesi Kandilli Rasathanesi ve Deprem Araştırma Enstitüsü'ne (KOERI) ve DANA dizisini desteklediği için Sakarya Üniversitesi'ne teşekkür ediyoruz. Çalışmada kullanılan Dense Array for North Anatolia (DANA) ve Kandilli Rasathanesi ve Deprem Araştırma Enstitüsü veri setleri referanslardaki web adreslerinden elde edilebilir. Şekillerin bazıları GMT yazılımı tarafından üretildi (Wessel ve Smith, 1995). Hesaplamalar için Python açık kaynak kodu kullanılmıştır. Çalışmaya verdiği katkılardan dolayı Dr. Öğr. Üyesi Ahmet Anıl Dindar ve Dr. Yaman Özakın'a teşekkür ederiz.

\section{Yazar Katkıları}

Ahu KÖMEÇ MUTLU: Analizi planlamış ve tasarlamış, veri toplamış, analizini yapmış ve makaleyi yazmaya katkı sağlamıştır.

Musavver Didem CAMBAZ: Analizi planlamış ve tasarlamış, veri toplamış, analizini yapmış ve makaleyi yazmaya katkı sağlamıştır.

\section{Çıkar Çatışması}

Yazarlar çıkar çatışması bildirmemişlerdir.

\section{Kaynaklar}

Altuncu Poyraz S., Teoman M. U., Türkelli N., Kahraman M., Cambaz D., Mutlu A., Rost S., Houseman G. A., Thompson D. A., Cornwell D., Utkucu M., and Gülen L., New constraints on micro-seismicity and stress state in the western part of the North Anatolian Fault Zone: Observations from a dense seismic array. Tectonophysics, 656, 2015.

Armijo R., Meyer B., Barka A., De Chabaler D. and Hubert-Ferrari A., The 1999 Izmit earthquake rupture and the tectonic evolution of the Sea of Marmara. EOS, Transactions American Geophysical Union, 80, F664, 1999 a.

Armijo R., Meyer B., Hubert A. and Barka, A., Westward propagation of the North Anatolian fault into the northern Aegean: timing and kinematics. Geology, 27, 267-270, 1999b.

Aslan, G., Lasserre, C., Cakir, Z., Ergintav, S., Özarpaci, S., Dogan, U., et al., Shallow creep along the 1999 Izmit earthquake rupture (Turkey) from GPS and high temporal resolution interferometric synthetic aperture radar data (2011-2017). Journal of Geophysical Research: Solid Earth, 124, 2218-2236. https://doi.org/ 10.1029/2018JB017022, 2019.

Barka A., Slip distribution along the North Anatolian fault associated with large earthquakes of the period of the period 1939-1967. Bulletin of the Seismological Society of America, 59, 521-589, 1996.

Barka A. and Kadinsky C., Strike-slip fault geometry in Turkey and its influence on earthquake activity. Tectonophysics, 7, 663-684, 1988.

Barka A., Akyuz H.S., Altunel E., Sunal G., Cakır Z., Dikbas A., Yerli B., Armijo R., Meyer B., de Chabalier J.B., Rockwell T., Dolan J.R., Hartleb R., Dawson T., Christofferson S., Tucker A., Fumal T., Langridge R., Stenner H., Lettis W., Bachhuber J. and Page W., The surface rupture and slip distribution of the 17 August 1999 Izmit earthquake (M7.4), North Anatolian fault. Bulletin of the Seismological Society of America, 92, 43-60, 2002.

Beck S and Zandt G, Continental lithospheric deformation along a major strike-slip fault zone: the central North Anatolian Fault Zone, Turkey. International Federation of Digital Seismograph Networks. Dataset/Seismic Network. 10.7914/SN/YL_2005, 2005.

Ben-Zion, Y, The response of two joined quarter spaces to $\mathrm{SH}$ line sources located at the material discontinuity interface, Geophys. J. Int., 98, 213-222, 1989.

Ben-Zion Y. and Andrews D. J., Properties and implications of dynamic rupture along a material interface, Bulletin of the Seismological Society of America, 88, 1085-1094, 1998.

Ben-Zion, Y., Malin, P., San Andreas fault zone head waves near Parkfield, California, Science, 251, 15921594, 1991. 
Bogazici University Kandilli Observatory And Earthquake Research Institute (2001): Bogazici University Kandilli Observatory And Earthquake Research Institute. International Federation of Digital Seismograph Networks. Dataset/Seismic Network. 10.7914/SN/KO https://doi.org/10.7914/SN/KO, 2001.

Cambaz M.D. and Karabulut H., Love-wave group velocity maps of Turkey and surrounding regions. Geophysical Journal International, 181, 502-520, 2010.

DANA Dense Array for North Anatolia. International Federation of Digital Seismograph Networks (FDSN). Dataset/Seismic Network. https://doi:10.7914/SN/YH_2012, 2012.

Delph, J.R., Biryol, C.B., Beck, S.L., Zandt, G., \& Ward, K.M., 2015. Shear wave velocity structure of the Anatolian Plate: anomalously slow crust in southwestern Turkey. Geophys J Int, 202, 261 - 276, 2015.

Dor O., Yildirim C., Rockwell T. K., Ben-Zion Y., Emre O., Sisk M. and Duman T.Y. (2008). Geologic and geomorphologic asymmetry across the rupture zones of the 1943 and 1944 earthquakes on the North Anatolian Fault: Possible signals for preferred earthquake propagation direction. Geophysical Journal International, 173, 483-504.

Elmas A. and Yiğitbaş E., Ophiolite emplacement by strike-slip tectonics between the Pontide Zone and the Sakarya Zone in northwestern Anatolia, Turkey, International Journal of Earth Sciences, 90, 257-269, 2001.

Emre Ö., Duman T. Y., Özalp S., Elmacı H., Olgun Ş., Şaroğlu F., Active fault map of Turkey with an explanatory text 1:125,000. General Directorate of Mineral Research and Exploration, Special Publication Series, 30, 2013.

Erturaç M.K., 2018a. Sakarya'nın Jeolojik Özellikleri. (Ed.Cercis İkiel ) Sakarya'nın Fiziki, Beşeri ve İktisadi Coğrafya Özellikleri.Sakarya Üniversitesi.ISBN.978-605-2238-05-9.

Erturaç M.K., 2018b. Sakarya'nın Jeomorfolojik Özellikleri. (Ed.Cercis İkiel ) Sakarya'nın Fiziki, Beşeri ve İktisadi Coğrafya Özellikleri.Sakarya Üniversitesi.ISBN.978-605-2238-05-9.

Frederiksen A.W., Thomson D.A., Rost S., Cornwell D.G., Gülen L., Houseman G.A., Kahraman M., Poyraz S.A., Teoman U.M., Türkelli N. and Utkucu M., Crustal thickness variations and isostatic disequilibrium across the North Anatolian Fault, western Turkey. Geophysical Research Letters, 42, 751-757, 2015.

Gülen L., Pınar A., Kalafat D., Özel N., Horasan G., Yılmazer M. and Işıkara A.M., Surface fault breaks, aftershocks distribution, and rupture process of the 17 August 1999 Izmit, Turkey, earthquake. Bulletin of the Seismological Society of America, 92, 230-244, 2002.

Kahraman M., Cornwell D.G., Thompson D.A., Rost S., Houseman G.A., Türkelli, N., Teoman U., Altuncu Poyraz S., Utkucu M. and Gülen L., Crustal-scale shear zones and heterogeneous structure beneath the North Anatolian Fault Zone, Turkey, revealed by a high-density seismometer array, Earth and Planetary Science Letters, 430, 2015.

Karabulut, H., Paul, A., Cambaz, D., Kömeç Mutlu, A., Aksari, D. \& Afacan Ergün, T., The images of Anatolia. In EGU General Assembly Conference Abstracts (Vol. 17), 2015.

Karabulut H., Paul A., Özbakır A.D., Ergün T., Şentürk S., (2019) A new crustal model of the AnatoliaAegean domain: evidence for the dominant role of isostasy in the support of the Anatolian plateau, Geophys. J. Int. (2019) 218, 57-73.

McClusky S., Balassanian S., Barka A., Demir C., Ergintav S.,Georgiev I., Gurkan O., Hamburger M., Hurst K. and Kahle H., Global Positioning System constraints on plate kinematics and dynamics in the eastern Mediterranean and Caucasus, Journal of Geophysical Research, 105(B3), 5695-5719, 2000.

Meade B. J., Hager B.H., McClusky S.C., Reilinger R.E., Ergintav S., Lenk O., Barka A. and Ozener H., Estimates of seismic potential in the Marmara Sea region from block models of secular deformation constrained by Global Positioning System measurements, Bulletin of the Seismolical Society of America, 92, 208-215, 2002.

Martinez-Garzon, P., Ben-Zion Y., Zaliapinc I., Bohnhoff M., Seismic clustering in the Sea of Marmara: Implications for monitoring earthquake processes, Tectonophysics Volume 768, 5 October 2019, 228176, 2019.

Mitchell T. M., Ben-Zion Y. and Shimamoto T. (2011). Pulverized fault rocks and damage asymmetry along the Arima-Takatsuki Tectonic Line, Japan. Earth and Planetary Science Letters, 308, 284-297.

Mutlu A.K, Karabulut H., 2011, Anisotropic Pn tomography of Turkey and adjacent regions, Geophys. 
J.Int.187.1743-1757, 2011.

Najdahmadi B., Bohnhoff M., Ben-Zion Y., Bimaterial interfaces at the Karadere segment of the North Anatolian Fault, northwestern Turkey. JGR Solid Earth., https://doi.org/10.1002/2015JB012601.

Nakamura A., Hasegawa A., Ito A., Üçer B., Baris S., Honkura Y., Kono T., Hori S., Pektas,R., Komut T., Çelik C. and Isikara A.M., P-wave velocity structure of the crust and its relationship to the occurrence of the 1999 Izmit, Turkey, earthquake and aftershocks. Bulletin of the Seismological Society of America, 92 (1), 330-338, 2002.

Okay A.I., Tectonic Units and Sutures in the Pontides, Northern Turkey. In: Şengör A.M.C. (eds) Tectonic Evolution of the Tethyan Region. NATO ASI Series (Series C: Mathematical and Physical Sciences), vol 259. Springer, Dordrecht, 1989.

Özakin Y., Ben-Zion Y., Aktar M., Karabulut H. and Peng, Z. (2012). Velocity contrast across the 1944 rupture of the North Anatolian fault east of Ismetpasa from analysis of teleseismic arrivals. Geophysical Research. Letters, 39.

Özbakır A., Govers R., Wortel R., Active faults in the Anatolian-Aegean plate boundary region with Nubia, Turkish J Earth Sci. 26: 30-56 TUBITAK doi:10.3906/yer-1603-4, 2017.

Özer, Ç., Polat, O., İzmir ve Çevresinin 3-B Kabuk Hız Yapısı. Gazi Üniversitesi Mühendislik-Mimarlık Fakültesi Dergisi, v. 32, n. 3, sep. 2017. ISSN 1304-4915. $\leq$ http://www.mmfdergi.gazi.edu.tr/article/view/5000183677>doi:http://dx.doi.org/10.17341/gummfd.06062, 2019.

Papaleo E., Cornwell D.G. and Rawlinson N., Seismic tomography of the North Anatolian Fault: New insights into structural heterogeneity along a continental strike- slip fault. Geophysical Research Letters, 44, 2017.

Reilinger R.E., McCLusky S.C., Oral M.B., King R.W. and Toksoz M.N., 1997. Global Positioning System measurements of the present day crustal movements in the Arabia-Africa-Eurasia plate collision zone. Journal of Geophysical Research, 102, 9983-9999, 1997.

Salah, M.K., Sahin, S., Kaplan, M., Seismic Velocity Structure along the Western Segment of the North Anatolian Fault Zone Imaged by Seismic Tomography. Bull. Earthq. Res. Inst. Univ. Tokyo 82, 209 223, 2007.

Şengör A.M.C., Gorur N. and Saroglu F., Strike-slip faulting and related basin formation, in zones of tectonic escape: Turkey as a case study, in Strike-Slip Faulting and Basin Formation: Society of Economic Paleontologists and Minerologists, Vol. 37, pp. 221-264, eds, Biddle, K.T. and Cristie Blick, N., Special Publication, 1985.

Şengör, A. M. C. ve Y1lmaz, Y., 1981. Tethyan evolution of Turkey: a plate tectonic approach. Tectonophysics, 75, 181-241.

Şengör A.M.C., Tuysuz O., Imren C., Sakınc M., Eyidogan H., Gorur N., Le Pichon X. and Rangin C. (2005). The North Anatolian Fault: A new look. Annual Review of Earth and Planetary Sciences, 33, $37-112$.

Tank S.B., Honkura Y., Ogawa Y., Matsushima M., Oshiman N., Tunçer M.K., Çelik C., Tolak E. and Işikara A.M., 2005. Magnetotelluric imaging of the fault rupture area of the 1999 İzmit (Turkey) earthquake. Physics of the Earth and Planetary Interiors, 150, 213-225, 2005.

Taylor G., Rost S., Houseman G. and Hillers G., Near surface structure of the North Anatolian Fault Zone from Rayleigh and Love wave tomography using ambient seismic noise. Solid Earth Discussion, 100, 2018.

Teoman U., Altuncu-Poyraz S., Kahraman M., Komec-Mutlu A., Cambaz M.D., Turkelli N., Thompson D.A., Rost S., Houseman G.A. and Utkucu M., New Insights on Seismicity and the Velocity Structure beneath the Western Segment of the North Anatolian Fault Zone. AGU Fall Meeting, 15-19 December 2014, San Francisco, Abstracts, S21E-05, 2014.

Tezel, T., T. Shibutani, and B. Kaypak, Crustal thickness of Turkey determined by receiver function, J. Asian Earth Sci., 75, 36-45, doi:10.1016/j.jseaes.2013.06.016, 2013.

Vanacore, E. A., T. Taymaz, and E. Saygin, Moho structure of the Anatolian Plate from receiver function analysis, Geophys. J. Int., 193, 329-337, doi:10.1093/gji/ggs107, 2013.

Wessel P. and Smith W.H.F., New version of the generic mapping tools (GMT). EOS Transactions American Geophysical Union, 76, 329, 1995. 
Yamashita T. (2009). Rupture Dynamics on Bimaterial Faults and Nonlinear Off-Fault Damage, ed: Fukuyama, E., 94, Elsevier, USA, 187-215, 2009.

Yılmaz Y, Tüysüz, O., Yiğitbaş, E., Genç, Ş. C., Şengör, A. M. C., 1997. Geology and tectonic evolution of the Pontides. In: Regional and Petroleum Geology of the Black Sea and Surrounding Region (ed. AG Robinson), Am. Assoc.Pet. Geol. Mem., 68, 183-266.

Zaliapin I. and Ben-Zion Y., Asymmetric distribution of aftershocks on large faults in California. Geophysical Journal International, 185, (3), 1288-1304, 2011. 